\title{
COPPER BRONZE POWDER SURFACE STUDIED BY XPS AND HR SEM
}

\author{
R. Shvab, E. Hryha, A. M. Tahir, L. Nyborg
}

\begin{abstract}
The state of the powder surface represents one of the main interests in the whole cycle of components' production using powder metallurgy (PM) route. Large specific surface area of the powder in combination with often alloying with oxygen sensitive elements results in oxidation of the powder surface in most of the cases. The information about surface chemistry of the powder is of vital importance for further consolidation and sintering steps. Surface sensitive analytical techniques - X-ray photoelectron spectroscopy (XPS) and high-resolution scanning electron microscopy combined with energy dispersive $X$-ray analysis (HR $S E M+E D X)$ were used for surface chemical analysis of the 60Cu-40Sn bronze powder. Determination of the compositional profiles and estimation of the surface oxide layer thickness was done by altering of ion etching and XPS analysis. The results showed tin oxide enrichment and presence of copper hydroxide on the surface of the powder particles. The impurities of $\mathrm{P}, \mathrm{Zn}$ and $\mathrm{Ca}$ were also detected on the top surface of the powder in trace amounts.

Keywords: 60Cu-40Sn bronze powder, surface oxides, X-ray photoelectron spectroscopy, high-resolution scanning electron microscopy.
\end{abstract}

\section{INTRODUCTION}

Components produced by casting, forming, shaping and even made by near-net or netshape methods, often require further operations before the product is ready for use. Machining, which involves secondary and finishing operations, is usually applied at the end of the manufacturing process to meet all the demands required for the component [1]. Grinding is one of the most important finishing operations because of its capability to impart high dimensional accuracy and surface finish. Grinding is a metal cutting process using tools with multiple cutting edges provided by randomly bonded abrasive grits of natural and/or synthetic origin which remove material at high speed. Metal-bonded grinding wheels use the metal bond to hold the abrasive grit (cubic boron nitride, diamond, etc.) for high performance applications. Using different powder metallurgy (PM) techniques, abrasive grits are mixed with metal bond powder and some additives and subsequent bonding is carried out under high pressure and temperature. The high thermal conductivity, strength and wear resistance of $\mathrm{Cu}$ bronze makes it an interesting candidate for the metal bond [1-4]. Taking into account a high specific surface area of the powder in comparison with the bulk material, surface chemical state is one of the most important aspects determining usability of powder for PM processing. Exposure of the powder to the oxygen

Ruslan Shvab, Eduard Hryha, Lars Nyborg' Department of Materials and Manufacturing Technology, Chalmers University of Technology, Rännvägen 2A, 41296 Göteborg, Sweden

Abdul Malik Tahir, 3M Västervik, Folkparksvägen 31, 59383 Västervik 
containing atmosphere inevitably results in formation of surface oxide species in order to minimize high surface energy of the powder. Chemical composition, morphology and distribution of the oxide phases on the powder surface determine the conditions required for oxide removal/redistribution in order to form strong inter-particle necks. Strong and defectfree inter-particle connections are required to reach high mechanical performance of the final component $[5,6]$.

Investigation of the powder surface by X-ray photoelectron spectroscopy (XPS) has proved to be a very effective tool for the determination of the chemical state of the elements present on the powder surface. Combination of XPS with high-resolution scanning electron microscopy (HR SEM) and energy dispersive X-ray analysis (EDX) allows us to obtain information on presence, morphology, composition and distribution of the different phases on the powder surface. These techniques enable evaluation of the distribution of the secondary phases on the nano-level (thickness of the surface oxide films, presence, size and distribution of the secondary phases, etc.), as well as powder surface morphology [5-9].

Present study is focused on the evaluation of the surface oxide state of the $60 \mathrm{Cu}$ $40 \mathrm{Sn}$ bronze powder using the abovementioned surface analysis methodology for the further design of a robust sintering process to reduce powder surface oxides and tailor the strength and porosity of sintered abrasive components.

\section{MATERIALS AND METHODS}

Copper based bronze powder prealloyed with $40 \mathrm{wt} \%$ of tin was used in this study. Powder was prepared by water atomization. Mean particles size is $\sim 20 \mu \mathrm{m}$.

The surface chemical analysis of the powder was performed by X-ray photoelectron spectroscopy using a PHI 5500 instrument (Perkin Elmer, Waltham, Massachusetts, USA). Specimen was prepared by mounting the experimental powder on a carbon tape prior to analysis. The base pressure in the analysis chamber was $\sim 10-9$ mbar. The analyzed area during XPS analysis was about $0.8 \mathrm{~mm}$ in diameter. Hence, more than 100 powder particles were analyzed at the same time giving statistically reliable average result which represents the general powder surface composition. Photoelectrons were generated by monochromatic Al $\mathrm{K} \alpha$ source (1486.6 eV). Selected region spectra were recorded covering the $\mathrm{Cu} 2 \mathrm{p}, \mathrm{Sn} 3 \mathrm{~d}, \mathrm{O} 1 \mathrm{~s}, \mathrm{C} 1 \mathrm{~s}, \mathrm{Zn} 2 \mathrm{p}, \mathrm{P} 2 \mathrm{~s}$ and $\mathrm{Ca} 2 \mathrm{p}$ photoelectron peaks. The acquisition conditions for such high-resolution spectra were $23.5 \mathrm{eV}$ pass energy with the step of $0.1 \mathrm{eV}$ and nominal take-off angle of $45^{\circ}$. Energy calibration using $\mathrm{Au} 4 \mathrm{f} 7 / 2(84.0$ $\mathrm{eV}), \mathrm{Ag} 3 \mathrm{~d} 5 / 2(368.3 \mathrm{eV})$ and $\mathrm{Cu} 2 \mathrm{p} 3 / 2(932.7 \mathrm{eV})$ was carried out on a daily basis under the same conditions as high-resolution spectra. It was estimated that the experimental error in binding energy was below $\pm 0.1 \mathrm{eV}$. Therefore, experimental error of the binding energy shift was smaller than this value. The recorded photoelectron peaks were curve fitted utilizing the PHI Multipak software (Perkin Elmer, Waltham, Massachusetts, USA) with asymmetric curves and assuming Shirley background [6].

Depth compositional profiling was done by altering of ion etching and XPS analysis. The ion etching was performed in argon gas with an accelerating voltage of $4 \mathrm{kV}$ and angle between the ion incidence and the sample surface of $\sim 50^{\circ}$. The Ar+ beam was rastered on the area of $4 \times 5 \mathrm{~mm}$ giving an etching rate of $3 \mathrm{~nm} \mathrm{~min}-1$. The etch rate was calibrated on a flat oxidized tantalum foil with the well-known Ta2O5 thickness $(100 \mathrm{~nm})$. Hence, the oxide thickness refers to $\mathrm{Ta}_{2} \mathrm{O}_{5}$ units [6] .

The morphology of the powder surface and composition of the secondary phases were analyzed on the powder samples by high resolution scanning electron microscopy (HR SEM) utilizing LEO Gemini 1550 (LEO GmbH, Oberkochen, Germany) equipped 
with an energy dispersive X-ray spectrometer (EDX) X-Max (Oxford Instruments Ltd., High Wycombe, UK).

\section{RESULTS AND DISCUSSION}

\section{XPS Analysis}

The survey spectrum of XPS analysis of the $60 \mathrm{Cu}-40 \mathrm{Sn}$ bronze powder indicates presence of carbon $(\mathrm{C} 1 \mathrm{~s})$, copper $(\mathrm{Cu} 2 \mathrm{p})$, strong tin $(\mathrm{Sn} 3 \mathrm{~d})$ and oxygen $(\mathrm{O} 1 \mathrm{~s})$ peaks, see Fig. 1. Beside these elements, traces of phosphorus (P2p and P2s), zinc (Zn2p) and calcium $(\mathrm{Ca} 2 \mathrm{p})$ were registered on the powder surface. Carbon peak is mostly connected with absorbed species and was decreasing with ion etching. Surprisingly enough, the intensity of copper was found much smaller in comparison to the intensity of tin on the as-received powder surface, see Fig. 1.

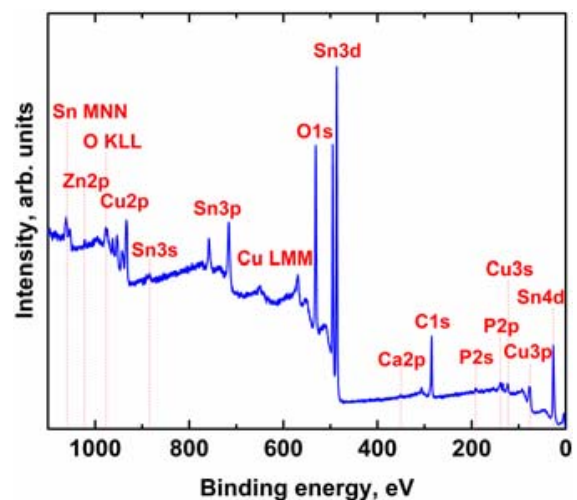

Fig.1. XPS survey spectrum of $60 \mathrm{Cu}-40 \mathrm{Sn}$ bronze powder in as-received state.

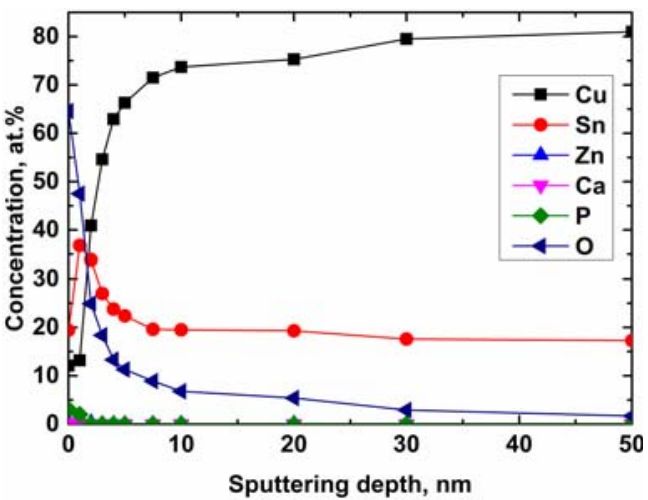

Fig.2. XPS analysis of the surface of $60 \mathrm{Cu}-$ 40Sn bronze powder vs. etch depth.

Tab.1. Chemical composition (at.\%) of the surface of the $60 \mathrm{Cu}-40 \mathrm{Sn}$ bronze powder vs. etch depth.

\begin{tabular}{|c|c|c|c|c|c|c|}
\hline $\begin{array}{c}\text { Etch depth, } \\
\text { nm }\end{array}$ & $\mathrm{Cu}$ & $\mathrm{Sn}$ & $\mathrm{Zn}$ & $\mathrm{Ca}$ & $\mathrm{P}$ & $\mathrm{O}$ \\
\hline as-received & 12.1 & 19.4 & 0.5 & 0.3 & 3.1 & 64.6 \\
\hline 1 & 13.2 & 36.8 & 0.4 & 0.1 & 2.0 & 47.5 \\
\hline 2 & 40.9 & 33.9 & 0.3 & 0.0 & 0.0 & 24.9 \\
\hline 3 & 54.6 & 27.0 & 0.0 & 0.0 & 0.0 & 18.4 \\
\hline 4 & 62.9 & 23.8 & 0.0 & 0.0 & 0.0 & 13.3 \\
\hline 5 & 66.3 & 22.4 & 0.0 & 0.0 & 0.0 & 11.3 \\
\hline 7.5 & 71.5 & 19.6 & 0.0 & 0.0 & 0.0 & 8.9 \\
\hline 10 & 73.7 & 19.5 & 0.0 & 0.0 & 0.0 & 6.8 \\
\hline 20 & 75.3 & 19.3 & 0.0 & 0.0 & 0.0 & 5.4 \\
\hline 30 & 79.5 & 17.6 & 0.0 & 0.0 & 0.0 & 2.9 \\
\hline 50 & 81.0 & 17.3 & 0.0 & 0.0 & 0.0 & 1.7 \\
\hline
\end{tabular}

Chemical state of the elements of interest - metallic or oxide state, formation of other species as carbides, etc. on the powder surface - can be obtained from high-resolution 
narrow scans over the binding energy ranges of the corresponding peaks. Analysis of the shifting in the binding energy gives the possibility to deconvolute corresponding contributions of the element in every state to the total intensity of measured peak. Concentration of the elements of interest at each etch depth was also calculated using highresolution spectra, see Fig.2 and Table 1.

Change in the chemical composition of the surface with etching depth indicates enrichment of the powder surface in oxygen, see Fig.2 and Table 1. Steep decrease in oxygen concentration is observed up to about $5 \mathrm{~nm}$ etch depth after which decrease in oxygen content become weaker. Removal of the surface contaminants - etching of $2 \mathrm{~nm}-$ results in significant decrease in carbon peak, which results in an increase in intensity of the peaks of copper and tin. Further etching results mostly in a significant decrease in the oxygen peak intensity, which also results in increasing of the intensity of copper and tin peaks. As is clear from the chemical composition depth profile, the contaminats $\mathrm{Zn}, \mathrm{Ca}$ and $\mathrm{P}$ are present only on the top surface and are completely removed after etching to $3 \mathrm{~nm}$ depth. $\mathrm{Ca}$ and $\mathrm{Zn}$ are present in trace amounts which do not exceed 0.5 at.\%, while concentration of $\mathrm{P}$ on the as-received surface is about 3 at.\%. Inhomogeneous distribution of the alloying elements on the powder surface is even more pronounced if only concentration of the alloying elements in oxide form is taken into account, see Fig.3.

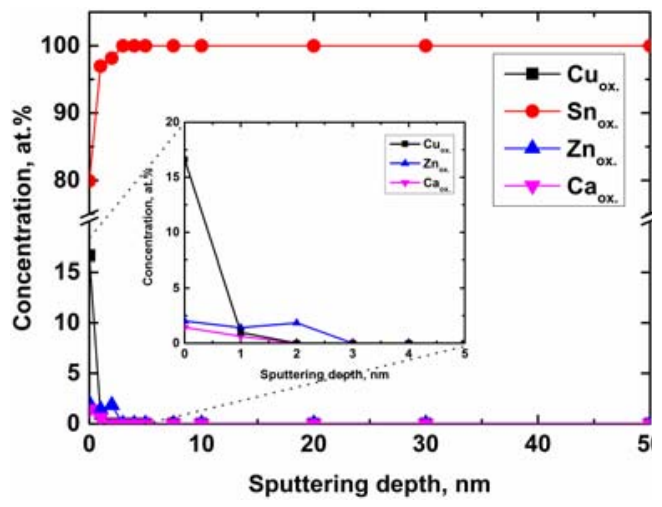

Fig.3. Oxide cations concentration on the surface of $60 \mathrm{Cu}-40 \mathrm{Sn}$ bronze powder vs. etch depth.

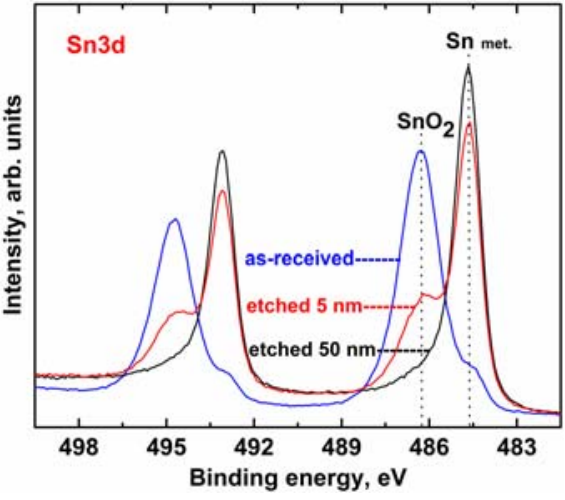

Fig.4. Position of the Sn3d peak in asreceived state and after etching to 5 and 50 nm.

Analysis of the peak position of Sn indicates its presence in an oxide state on the as-received surface that is mostly removed after ion etching up to $5 \mathrm{~nm}$ and at the final etch depth only pure metallic peak of tin is observed, see Fig.4. Weak shoulder at around 484.7 $\mathrm{eV}$ in the $\mathrm{Sn3d}$ spectrum recorded on the as-received surface corresponds to the metallic peak of tin and indicates small oxide layer thickness.

Despite much higher amount of copper in the alloy, its concentration on the powder surface was about 2 times lower than for tin. Analysis of the peak position of $\mathrm{Cu}$ on the as-received surface indicates its presence in 2 chemical states $-\mathrm{Cu}^{0}$ and $\mathrm{Cu}^{2+}$, see Fig.5. According to M.C. Biesinger et al. [10], $\sim 2 \mathrm{eV}$ higher binding energy than of metallic copper and presence of shake-up peak clearly indicates copper hydroxide. After etching to $1 \mathrm{~nm}$, the hydroxide component in the $\mathrm{Cu} 2 \mathrm{p}$ peak disappears and copper is further present only in the metallic state. Comparison of the shape and peak position of oxygen in the asreceived state and after etching to $1 \mathrm{~nm}$, see Fig.6, also shows a much higher amount of 
hydroxide on the as-received surface, that decreases significantly after etching. Metallic copper signal on the as-received surface also reveals that oxide layer on the powder surface is thin.

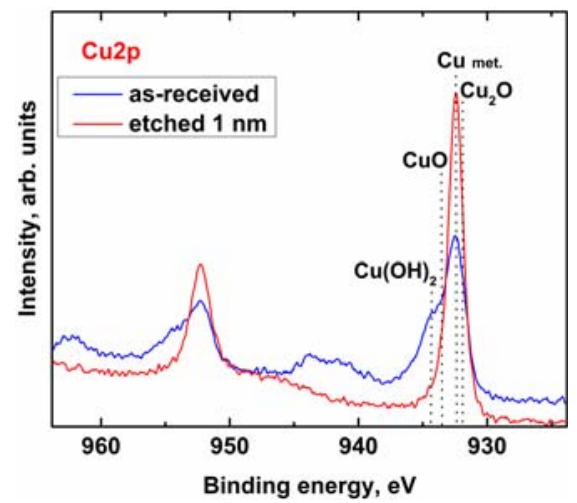

Fig.5. Position of the $\mathrm{Cu} 2 \mathrm{p}$ peak in asreceived state and after etching to $1 \mathrm{~nm}$.

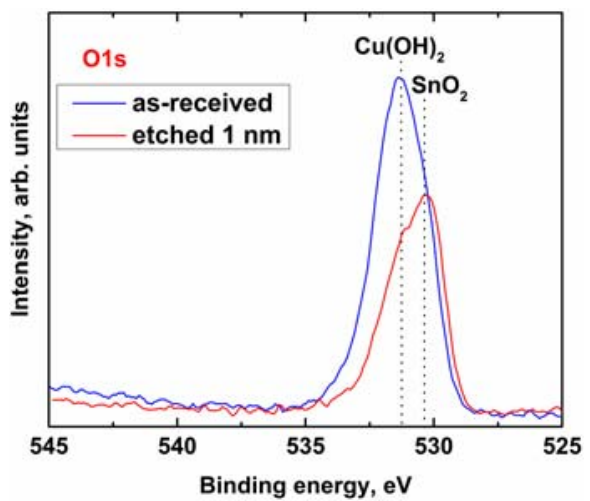

Fig.6. Position of the O1s peak in asreceived state and after etching to $1 \mathrm{~nm}$.

Depth composition profile shows that the relative concentration of oxygen decreases with etching depth with significant drop after about $5 \mathrm{~nm}$, see Fig.2. Un-etched (shaded) areas of powder particles during Ar-etching and possible presence of Sn-rich oxides are assumed to be responsible for residual oxide traces present after final etching to $50 \mathrm{~nm}$. Fig.7 illustrates the relative intensities of metallic tin and copper together with oxygen vs. etch depth. Intensity of the metallic peaks at every etch depth was obtained by extraction of the metal intensity peak from the intensity of superimposed $\mathrm{Sn}$ and $\mathrm{Cu}$ peaks from high energy resolution narrow scans. The profiles of metallic $\mathrm{Cu}$ and $\mathrm{Sn}$ allow us to assume presence of a thin copper hydroxide layer and particulate Sn-rich oxides on the powder surface. The copper hydroxide thickness estimated from the etch time where the oxygen intensity has declined to half its initial value, indicates to be $\sim 1.4 \mathrm{~nm}$, see Fig. 7 .

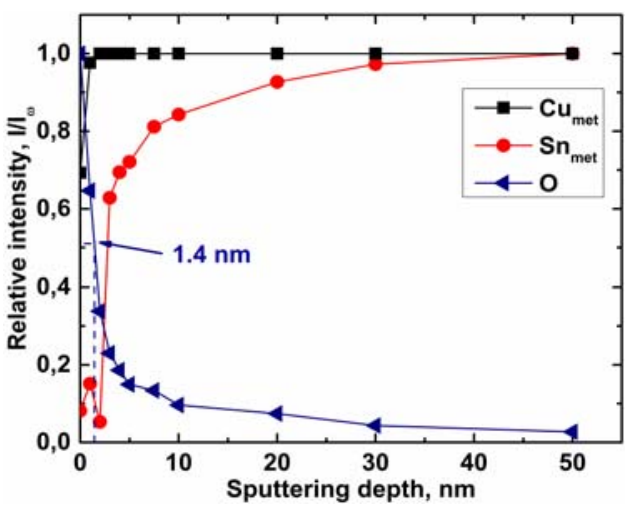

Fig.7. The normalized intensity of Cu-metal $\left(\mathrm{Cu} 2 \mathrm{p}_{3 / 2}\right.$-peak), Sn-metal ( $\mathrm{Sn} 3 \mathrm{~d}_{5 / 2}$-peak) and oxygen (O1s-peak) vs. etch depth, indicating surface oxide layer thickness of $\sim 1.4 \mathrm{~nm}$.

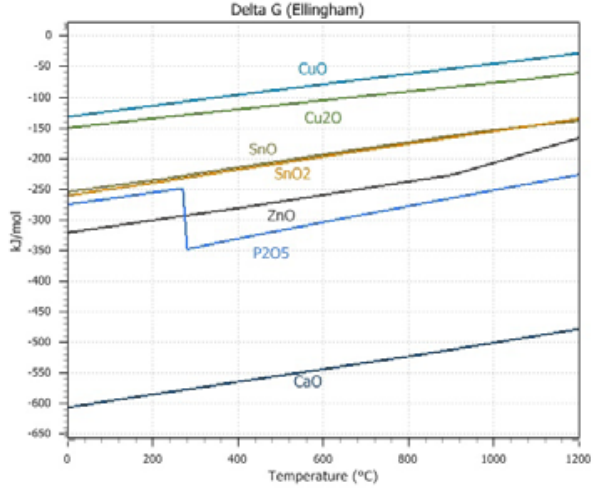

Fig.8. The Richardson-Ellingham diagram, showing stability of different oxides, present in the system. 
Presence of Sn-rich particulate oxides on the surface of $60 \mathrm{Cu}-40 \mathrm{Sn}$ bronze powder can be explained by a high affinity of tin to oxygen according to the Richardson-Ellingham diagram, see Fig.8. Tin oxide particles, that are thermodynamically more stable than copper oxides, on the powder surface can prevent formation of the inter-particle connections during sintering. The problem can be solved by using reducing atmospheres containing hydrogen [11].

\section{HR SEM And EDX Analysis}

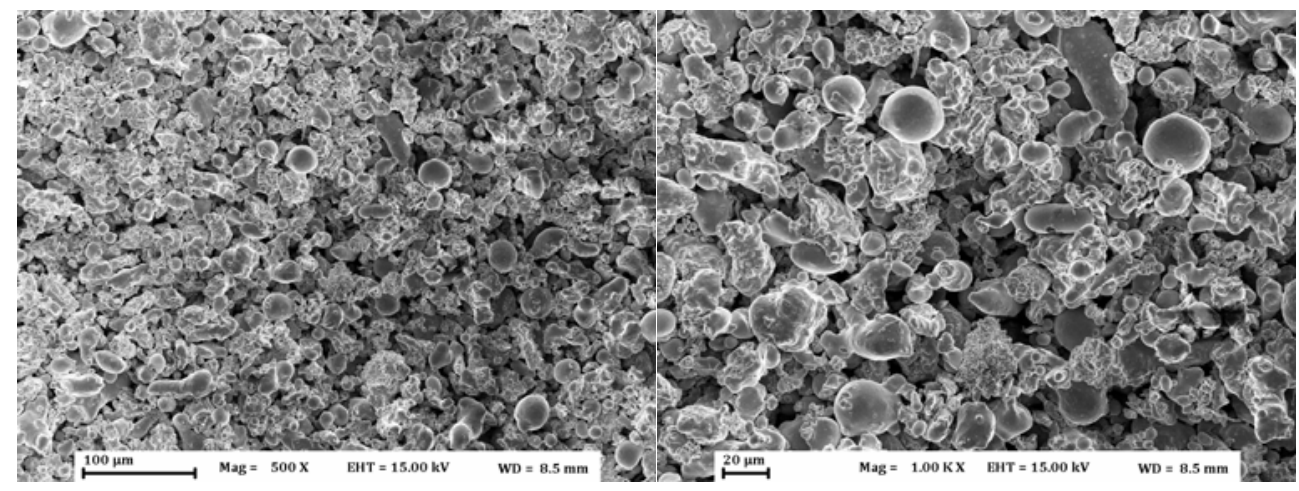

Fig.9. SEM images showing appearance of $60 \mathrm{Cu}-40 \mathrm{Sn}$ powder.
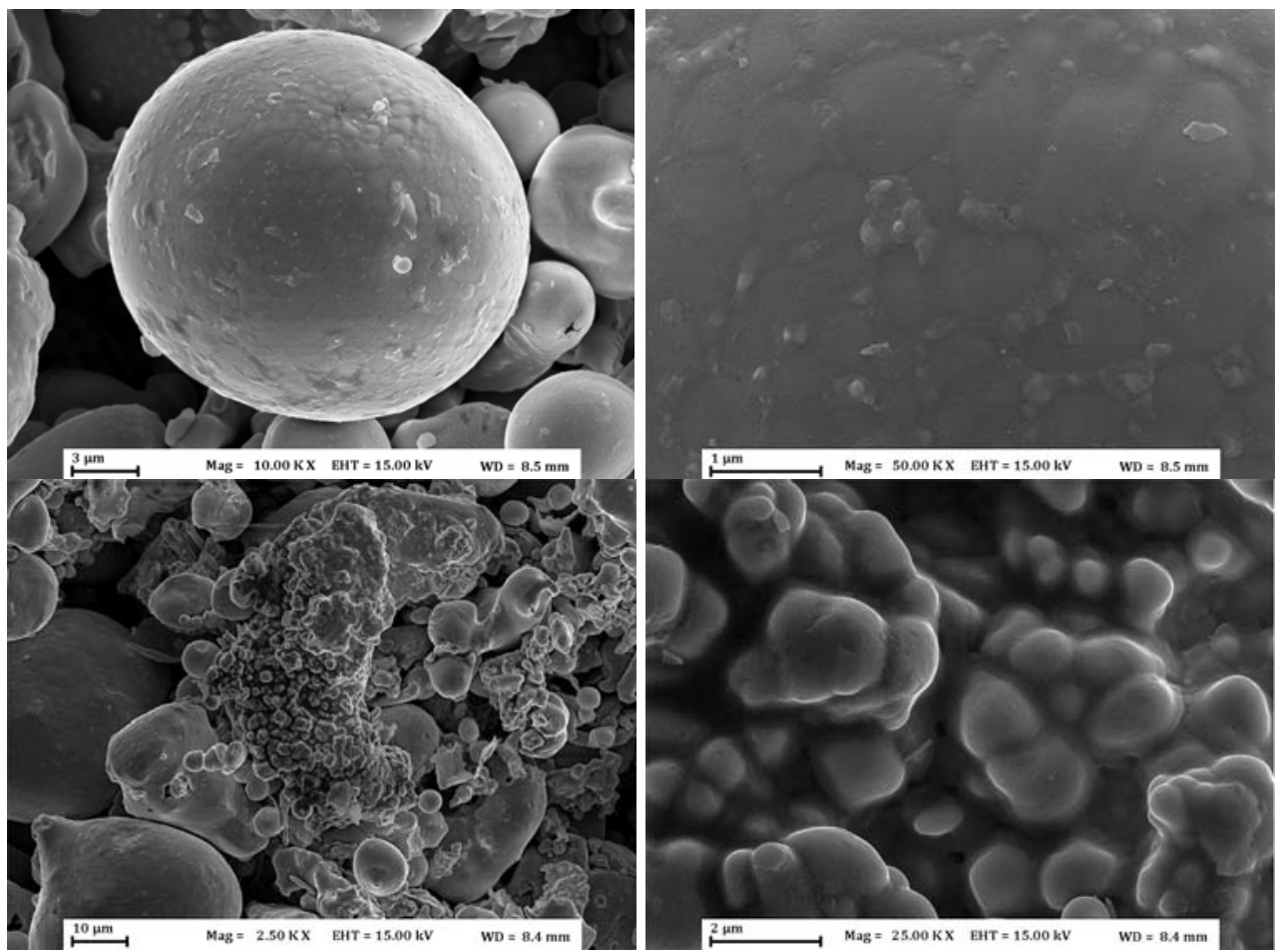

Fig.10. SEM images showing morphology and distribution of particulates on the surface of $60 \mathrm{Cu}-40 \mathrm{Sn}$ powder. 
According to HR SEM analysis, the $60 \mathrm{Cu}-40 \mathrm{Sn}$ bronze powder consists of a mixture of spherical and irregular particles, see Fig.9. The typical appearance of the powder surface, shown in Fig.10, confirms results obtained by XPS analysis. Particulate features are present on the powder surface and are preferantially located on the grain boundaries. Grain boundaries are clearly visible on the powder surface, showing the grain size of about $1 \mu \mathrm{m}$.
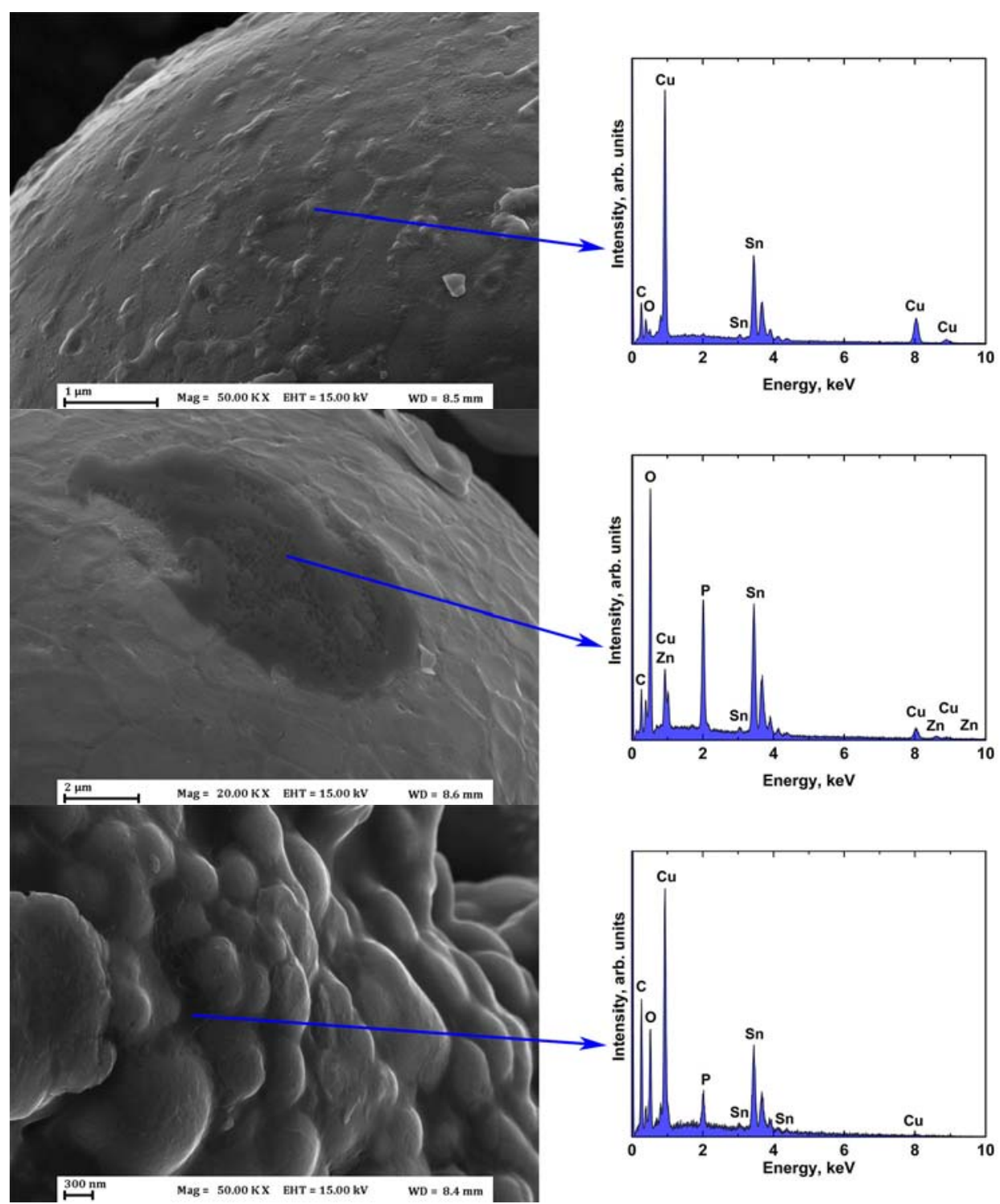

Fig.11. Qualitative SEM + EDX analyses of the features on the surface of $60 \mathrm{Cu}-40 \mathrm{Sn}$ powder.

Detailed analysis of the powder with EDX analysis shows that particulate features on the powder surface have tin oxide nature, see Fig.11. Small amount of "flake-like" dark 
areas containing $\mathrm{P}$ and $\mathrm{Zn}$ were also detected on the powder surface, indicating the presence of zinc phosphate.

\section{CONCLUSION}

The surface of the $60 \mathrm{Cu}-40 \mathrm{Sn}$ bronze powder is covered by thin uniform copper hydroxide layer with a presence of islands formed by $\mathrm{Sn}, \mathrm{P}, \mathrm{Ca}$ and $\mathrm{Zn}$ oxides. Surface copper hydroxide has average thickness of about $1.4 \mathrm{~nm}$. HR SEM + EDX analysis indicates that the powder consists of a mixture of spherical and irregular particles. Powder particles have fine grain structure, with the grain size of $\sim 1 \mu \mathrm{m}$ and are decorated by Snrich complex particulate oxide phases on the surface of spherical powder particles. Two types of particulates can be observed on the powder surface - fine particulate Sn oxides, preferantially located at grain boundaries and "flake-like" areas of dark phases which contain $\mathrm{P}$ and $\mathrm{Zn}$.

\section{Acknowledgement}

Support from the Chalmers Areas of Advance in Materials Science and Production, as well as funding from the strategic innovation program LIGHTer, provided by Vinnova, are gratefully acknowledged.

\section{REFERENCES}

[1] Kalpakjian, S., Schmid, SR.: Manufacturing engineering and technology. 6th ed. Pearson Education South Asia Pte Ltd, 2010

[2] Boothroyd, G., Knight, WA.: Fundamentals of machining and machine tools. 3rd ed. Marcel Dekker, 2006

[3] Malkin, S., Guo, C.: Grinding technology: theory and applications of machining with abrasives. 2nd ed. Industrial press, 2008

[4] Rowe, WB.: Principals of modern grinding technology. 2nd ed. Elsevier, 2014

[5] Hryha, E., Gierl, C., Nyborg, L., Danninger, H., Dudrova, E.: Appl. Surf. Sci., vol. 256, 2010, p. 3946

[6] Hryha, E., Shvab, R., Bram, M., Bitzer, M., Nyborg, L.: Appl. Surf. Sci., in press, doi:10.1016/j.apsusc.2016.01.046

[7] Nyborg, L., Nylund, A., Olefjord, I.: Surf. Interface Anal., vol. 12, 1988, p. 110

[8] Oikonomou, C., Nikas, D., Hryha, E., Nyborg, L.: Surf. Interface Anal., vol. 46, 2014, p. 1028

[9] Chasoglou, D., Hryha, E., Norell, M., Nyborg, L.: Appl. Surf. Sci., vol. 268, 2013, p. 496

[10] Biesinger, MC., Lau, LWM., Gerson, AR.: Smart, Appl. Surf. Sci., vol. 257, 2010, p. 887

[11] Andersson, R., Holm, T., Wiberg, S.: Furnace atmospheres No2: Neutral hardening and annealing. Special edition, Linde gas 